\title{
Provision of chlamydia testing, and training of primary health care staff about chlamydia testing, across four European countries
}

Anneli Uusküla ${ }^{1 *}$, Ellie J Ricketts ${ }^{2}$, Claire Rugman ${ }^{2}$, Ruth R Kalda ${ }^{3}$, Hans Fredlund ${ }^{4}$, Johan Hedlund ${ }^{5}$, Brigitte Dunais ${ }^{6}$, Pia P Touboul ${ }^{6}$ and Cliodna McNulty ${ }^{2}$

\begin{abstract}
Background: The objectives of this study were to describe and compare chlamydia testing provided by general practitioners (GPs) in four selected European countries with well-developed primary health care systems and high reported chlamydia rates; we aimed to compare contrasting countries where chlamydia testing is provided by GPs (England, Sweden) with countries where primary care chlamydia testing is absent or very limited (France, Estonia).

Methods: For data generation a structured questionnaire was developed and secondary data sources were searched. The questionnaire developed by the research team allowed a systematic approach to analysing chlamydia care (including testing in general practice) and the gathering of relevant data.

Results: There were no significant differences in the burden of the disease or the type of general practice care provision in the study countries. In all four countries, testing for chlamydia (with nucleic acid amplification test, NAAT) is available in the public sector, a substantial proportion $(>60 \%)$ of young people aged $16-25$ years visit their general practitioner (GP) annually, and reimbursement for chlamydia testing costs to the relevant parties (GPs in England, Sweden and Estonia; and patients in France) by the national health insurance system or its equivalent. In countries where chlamydia testing is provided by GPS (England, Sweden) a national strategy or plan on STI control that specifically mentions chlamydia was in force, chlamydia care guidelines for GPs were in place and STI management was more firmly established in the GP residency training curriculum, either formally (England) or informally (Sweden), than in the other countries.
\end{abstract}

Conclusion: Future research on the effectiveness of chlamydia screening (also in the context of general practice care) and program provision should reflect national needs and the prevention of complications.

Keywords: Chlamydia, Testing, Training, General practice, Europe

\section{Background}

As the most frequently reported notifiable communicable disease in Europe and North America, chlamydia is the focus of concerted public health control efforts based on screening and treatment [1,2]. A systematic survey of chlamydia control activities conducted recently in 28 European Economic Area (EEA) countries [3] found wide variation in the organisation of chlamydia control: $60 \%$ $(17 / 28)$ of countries reported no organised activity, while $39 \%(11 / 28)$ of countries had a strategy or plan for sexually

\footnotetext{
* Correspondence: anneli.uuskula@ut.ee

${ }^{1}$ Department of Public Health, University of Tartu, Tartu, Estonia

Full list of author information is available at the end of the article
}

transmitted infections (STI) control in place (in 6 of those 11 chlamydia control was specifically mentioned in the strategy or plan). In 2012, clinical guidelines for chlamydia case management were available in $79 \%$ of these countries (22/28); including guidelines specifically for general practice or primary care physicians (GP) in $46 \%$ of the countries (13/28) [3]. Opportunistic testing of asymptomatic individuals was recommended in guidelines of $39 \%$ of countries $(11 / 28)$ but the UK is the only country with an organised chlamydia screening programme after the Netherlands stopped its pilot programme in 2012 [3].

Effective diagnosis and treatment of people with symptoms suggestive of chlamydia, followed by tracing and 
treatment of their recent sexual partner (s) is good clinical practice at the individual level [4]. However as the majority of infected people are asymptomatic and partner notification is often incomplete infected individuals can continue to transmit chlamydia to re-infect an existing partner, or to infect a new sexual partner. Therefore, if used alone symptomatic case management is unlikely to have an impact on chlamydia prevalence or long-term complications at the population level. Approaches for chlamydia control at the public health level include primary prevention activities, increased access to testing and treatment for people with or at risk of infection, and screening either opportunistically or as part of an organized population screening program. The effectiveness and the best approach to screening (where and whom to screen, how often, and what level of screening uptake is required to reduce prevalence in practice) is not yet clear.

A diversity of services might be required to provide comprehensive access to patients with, or at risk of, infection. General practitioners are potentially significant providers for chlamydia testing and screening [5-7]. Especially acknowledging the recent technological developments (e.g. nucleic acid amplification test (NAAT) based testing of non-invasive genital specimens) and wider access to adolescent/young adult population groups than for many other medical specialists [8-10].

The objectives of this study were to describe and compare chlamydia testing provision in four selected European countries with well-developed primary health care systems and high (reported) chlamydia rates; we aimed to compare contrasting countries where chlamydia testing is provided by GPs (England, Sweden) with countries where primary care chlamydia testing is absent or very limited (France, Estonia).

\section{Organisation of primary care/general medicine in participating countries England}

Health care in the United Kingdom (UK) has been centrally funded through the National Health Service (NHS). The NHS provides both primary and specialist health care which is largely free at the point of delivery. Recent reforms include a wide range of national quality improvement initiatives and a pay for performance scheme that accounts for around 25\% of family practitioners' income. General practitioners are responsible for registered populations of patients. The practices staffing varies in size from single general practices (GPs) to large practices with 20 or more staff (typically working in groups of 4-6 selfemployed physicians). They hire nurses and a range of other ancillary staff, and act as gatekeepers to most specialist care [11]. Patients may also directly access specialist genito-urinary medicine, out of hours primary care and emergency services which are usually based in the hospital setting. Practice list sizes therefore vary between $\sim 500$ to 20,000 or more.

The core general practitioner (GP) contract is managed by NHS England, and additional public health services including sexual health are commissioned by local authorities. Some local authorities offer additional payments for an enhanced level of service provision. Patients can choose to register with any practice that covers the area they are resident in and everyone can access NHS GP services without charge. Certain services which are not considered necessary or cost effective such as travel vaccinations, cosmetic and minor surgery are not provided on the NHS.

\section{Estonia}

The Health Services Organization Law of 2002 established the regulatory framework for primary care and family medicine whereby primary care is organized as the first level of contact with the health system and is provided by independent general practitioners (in Estonia: family physicians) -- who are contracted by the Estonian Health Insurance Fund and paid according to the number of patients registered on the list (according to a weighted per capita payment system) and fee-forservice. Since 2006, basic allowances have been complemented by a quality bonus system, which aims to foster disease prevention and management of selected chronic conditions. The regulations specify that a practice list size should be around $1600 \pm 400$ persons. Patients are free to choose the general practitioner with which they register, and can change their GP when they wish. All GPs are required to work with at least one practice nurse (in order to receive payment from the Estonian Health Insurance Fund). The income from the Estonian Health Insurance Fund is used by the family physician to meet the practice running costs, purchase of equipment, cost of essential diagnostics, and for remuneration of employed staff (such as nurses or administrative staff). In Estonia, GPs work as partial gatekeepers: referral from a GP is needed for almost all specialist care, except for (dermato)venerology, psychiatry, ophthalmology, gynaecology and traumatology in the case of acute trauma.

\section{France}

There is no general law defining primary care in France. Most health care providers in primary care working in private practice are regulated by a contract between the GP and the national health insurance.

Most primary care providers work on a fee for service basis. In order to be optimaly refunded, each citizen has to register with a doctor designated as their attending physician", the patient has to attend this doctor in order to be reimbursed in case of referral to some other specialists (but not for consultation with gynaecologists, paediatricians, ophthalmologists or psychiatrists). Most 
people are registered with a doctor (84\%), and nearly all of these are with a GP (98\%). There is no capitation fee related to the contract, and no commitment of any kind either for the doctor, or the patient, and no duration for the contract (patients can change "médecin traitant" at any time). GP practices are mainly single-handed. The number of group practices is increasing but very few of them include other healthcare providers (nurses, specialists, psychotherapists) [12].

\section{Sweden}

Primary care, delivered by public (owned by the county councils) and private (mostly owned by companies or cooperation) primary care units in Sweden, involves services that do not require advanced medical equipment and is responsible for guiding the patient to the right level within the health system. Team-based primary care facilities with four to six GPs, and other staff categories (district nurses, nurses and often physiotherapists, occupational therapists, psychologists, and social welfare counsellors), is the most common form of primary care practice in Sweden. Ideally, each GP will have 1,500 patients registered, in fact most have 2,000 or more registered patients in care.

Payment to primary care providers is generally based on capitation for registered patients, weighted with their estimated 'illness burden', fee-for-service and performance-based payments [13]. Primary care in Sweden for most surgeries falls within the budget of the County Council. Either the GPs and staff are employed by the County Council or they are private with a contract with the County Council.

\section{Methods}

The methods for collection and analysis of the data was agreed between the research team members and are presented below. The design was a cross-sectional review to collect national level data from participating countries.

\section{Research team}

The participating researchers from 4 countries brought to the team different perspectives and expertise. The study team consisted of a university researcher in public health/ dermatovenerologist (STI physician) (AU; Estonia), a general practitioner (RK; Estonia); a County Medical Officer (HF; Sweden) and a Registered Nurse for Communicable Diseases (JH; Sweden); two public health physicians (BD and PD; France), and a consultant microbiologist $(\mathrm{CMcN}$; England) and a primary care researcher (EJR; England).

For data generation a structured questionnaire was developed and secondary data sources searched. A structured questionnaire developed by the research team allowed a systematic approach to analysing the chlamydia care (including testing in general practice) and the gathering of relevant data.
The rationale for this analysis and methodology were evaluated by 8 study team members and discussed during research meetings throughout the analysis development process.

\section{Questionnaire development}

A structured questionnaire was developed by the study team and discussed at a face to face meeting in English (Additional file 1). The questionnaire asked about: the occurrence of chlamydia cases reported in participating countries; national data on the existence and content of guidelines on the management of chlamydia; details of programmes for surveillance and how data was collected; chlamydia care provision across the health service; and primary health care provision. In addition, specifically for general practice settings, the following information was obtained: volume of practice participation in chlamydia screening; how GP staff usually managed chlamydia and laboratory diagnosis, payment of GP staff for chlamydia and STI care.

The research team representatives in each country were asked to fill in the questionnaire and to ask other local experts (general practitioners, commissioners of sexual health services, public health practitioners, medical education specialists, health administrators) for help if they were uncertain of the answers themselves. Representatives were also asked to send background information, such as strategy documents and guidelines. Following the face to face meeting the questionnaire was finalised and emailed in February 2013 to the study researchers in each country. A member of the research team (AU) monitored answers, responded to questions and sent reminders. A bias in the analysis was mitigated in each country by another health professional with a national interest in sexual health (for example in England the National Chlamydia Screening Programme) or GP care provisjon (for example from Department of Family Medicine of the University of Tartu) checking the responses, and by detailed review of the data at a face to face meeting and several teleconferences and by email by the research team.

Country representatives reviewed the preliminary analysis; the data used in this report include all responses, amendments and clarifications received by September 2013.

Background data from secondary sources were collated, and included a review of published literature relating to chlamydia management in the selected countries. This analysis was supplemented by documentary analysis of published reports, key legal instruments and policy documents (European CDC reports on STI surveillance and chlamydia control [14,15]; country specific surveillance and administrative data as necessary). To assess the publication productivity (number of publications) of countries on chlamydia research and specifically on chlamydia 
research in primary care for the period of 1991 to 2013 a systematic literature search was conducted in PubMed using the following search terms: all - ("chlamydia"[$\mathrm{MeSH}$ Terms] OR "chlamydia"[All Fields]) AND ("1991"[CRDAT]: “3000"[CRDAT]) AND "humans" [MeSH Terms] AND [country]; GP setting - ("chlamydia" [MeSH Terms] OR "chlamydia"[All Fields]) AND (“1991”[CRDAT]: “3000”[CRDAT]) AND "humans"[MeSH Terms] AND "general practice”[MeSH Terms] OR ("general"[All Fields] AND "practice”[All Fields]) OR "general practice"[All Fields] AND [country].

The study team conducted systematic debriefings and cross-comparisons of the data compiled and its interpretation. Discrepancies between the researchers in interpretation were followed by in-depth discussion about the observations that led to those conclusions and additional data collection or consultations until the discrepancy was resolved.

The analysis presented here is based on the use of data or records that contain only non-identifiable data about people, e.g. publicly accessible records, archives or publications. The ethics committee of the University of Tartu has waived the requirement for ethics approval as this does not constitute research on human subjects. The study procedures were in accordance with local data protection regulations in all participating countries.

\section{Results}

\section{Occurrence of chlamydia in study countries}

Data on the incidence (number of reported cases in the population) and prevalence of genital chlamydia infection based on population-based studies is presented in Table 1. Sweden has the highest rate of chlamydia infections per 100,000 reported by surveillance. Availability of surveillance data from France is limited. According to the rate of new cases among 18-24 year olds in France (240-360/100,000), the estimated rate for all ages in France is likely to be similar to that reported from Estonia, rather than that in the England or Sweden. Chlamydia prevalences (derived from population based studies) range from 3.2\% (France) to 6.2\% (England) for women and $2.5 \%$ (France) to $5.3 \%$ (England) for men [16-19]. In the population-based studies, the gender differences of chlamydia prevalence in these countries were insignificant.

Only a small fraction of the research on chlamydia has focused on care issues in general practice settings ( $<8 \%$ of the total research production on chlamydia in England; 1\% in France and Sweden).

\section{Chlamydia care and management in participating countries}

There are written guidelines for health professionals (not necessarily primary care) covering diagnosis and case management of chlamydia in three of the four countries (England [7,20], Sweden [21], Estonia [22]. In France, there are recommendations published by the national health authority for chlamydia laboratory diagnostics and screening [23,24]. In these guidance documents chlamydia screening (i.e. testing of asymptomatic individuals) is recommended in all four countries for selected target groups: youth (England, France), pregnant women (Sweden, Estonia) and those exhibiting high risk sexual behaviour (England, Sweden, France). Retesting after positive chlamydia test (chlamydia treatment) is recommended at 3 months for all positive tests to check for repeat infection (in England), or for test of cure (in Sweden, Estonia). Partner notification and testing is also

Table 1 Occurrence of genital chlamydial infection and research on chlamydia in study countries

\begin{tabular}{|c|c|c|c|c|}
\hline & England & Estonia & France & Sweden \\
\hline $\begin{array}{l}\text { Number of reported cases, } \\
\text { all age groups, } 2010\end{array}$ & 215501 (206 912 in 2012) & 1686 (1 596 in 2012) & Data not available & 36800 (37 700 n 2012) \\
\hline $\begin{array}{l}\text { Rate per } 100000 \text { population, all age } \\
\text { groups, in } 2010 \text { (and 2012) }\end{array}$ & $\begin{array}{l}348 / 100000 \\
\left(1979 / 100000 \text { in } 2012^{*}\right)\end{array}$ & $\begin{array}{l}126 / 10000(119 / 100000 \\
\text { in 2012) }\end{array}$ & $\begin{array}{l}360 \text { for women } 240 \text { for } \\
\text { men (aged 18-24, in 2006)** }\end{array}$ & $\begin{array}{l}391 / 100000 \\
(395 / 100000 \text { in 2012) }\end{array}$ \\
\hline $\begin{array}{l}\text { Trend (chlamydia rate per } \\
100000 \text { in 2006) [14] }\end{array}$ & Increasing (190/100 000) & Decreasing (188/100 000) & NA & Increasing (360/100 000) \\
\hline $\begin{array}{l}\text { Chlamydia trachomatis prevalence } \\
\text { (population-based studies) }\end{array}$ & $\begin{array}{l}6.2 \% \text { in women and } \\
5.3 \% \text { in men [17] } 4.5 \% \\
\text { in women and } 4.4 \% \\
\text { in men [18] }\end{array}$ & $\begin{array}{l}6.0 \% \text { in women and } \\
4.0 \% \text { in men [19] }\end{array}$ & $\begin{array}{l}3.2 \% \text { in women and } \\
2.5 \% \text { in men }[16]\end{array}$ & No data \\
\hline $\begin{array}{l}\text { Research on chlamydia: number of } \\
\text { publications referenced in PubMed, } \\
\text { 1991-current (all publications on } \\
\text { chlamydia/publications } \\
\text { on chlamydia where GP settings are } \\
\text { specified or mentioned (\% of all)) }\end{array}$ & 1092/ $85(7.8 \%)$ & $16 / 1(6.3 \%)$ & $343 / 4(1.2 \%)$ & $460 / 5(1.1 \%)$ \\
\hline
\end{tabular}

*Data for 2012: England - Chlamydia Testing Activity Dataset 2012 (http://www.chlamydiascreening.nhs.uk/ps/data.asp); Estonia - Health board (http://www.terviseamet. ee/nakkushaigused/nakkushaigustesse-haigestumine.html); Sweden - Swedish Institute for Infectious Control.

**Extrapolated from the Goulet V et al. 2011 [32]. 
advocated in the chlamydia care guidelines for all health care providers (Estonia, France), or in guidelines for sexually transmitted infections/genitourinary medicine (STI/GUM) clinics (England). Sweden has specific partner notification guidelines [25]. Laboratory-based (England) and provider-based (Estonia, Sweden) infectious diseases surveillance systems for chlamydia are in place in three countries (England, Sweden, Estonia). A national screening program is in operation in England (Table 2) and has been pilot tested in France as part of a recent campaign by the Health Education Institute (the results from the campaign have not yet been made public).

Delivery of chlamydia care is spread between several health care settings: STI/GUM clinics (England; main site for men in Sweden, and in Estonia), gynaecology services (main site for women in Estonia), general practitioners (Sweden, England) and youth/family planning clinics (France, youth in Estonia, Sweden) (Table 2). Internet-based self-sampling is also available in England (a free service, FreeTest Me, is available), Sweden (a free service in the majority of counties), and Estonia (not free of charge).

\section{Primary care provision and chlamydia care in participating countries}

There are some clear similarities in the structure of GP care provision in England, Estonia and Sweden. Small group (2-3 GP) practices are the typical setting for primary care provision, although in England, a sizeable proportion of practices are larger (38\% - medium 5-9 GPs). In contrast, the typical GP service in France would be a single-handed practice. In England, Sweden and Estonia, nurses work in GP practices, but not in France (Table 3). Over two thirds of the youth at target age (16-24 years old) visit their general practitioner at least once a year [26-28].

The official policy of GP training in STI care (including chlamydia) varies in the 4 countries - from no training during GP residency (France), training some GPs but not all (England), to some training offered to all GPs (Sweden, Estonia), whether formally required (Estonia) or not (Sweden) (Table 3).

Provision of chlamydia care (testing, treatment, counselling) in GP services is regularly done in England and Sweden however in Estonia and France only a small proportion of GP practices provide chlamydia care (Table 4). For men self-taken specimens (urine) and for women physician-collected (cervical) swabs are the sampling methods of choice (with an exception of Sweden where for women self-collected vaginal swabs are used, and England where women are either asked to use a selfcollected vaginal swab or urine test). For genital chlamydia infection testing, urine is generally collected from men for both symptomatic disease and screening. For women, physician-collected cervical swabs are advised for symptomatic cases and self-collected vaginal swabs for screening purposes (Table 4).

\section{Payment for chlamydia care in GP settings}

Payment of health care services for the diagnosis and treatment of individuals with chlamydia for GPs varies in the study countries (Table 5). National insurance (Estonia) or a National health managing system (England, Sweden) reimburses the costs to GPs. In these countries, GPs are expected to provide most health care (including chlamydia care) within a particular budget per patient. Importantly there are local drivers that potentially modify chlamydia testing in general practices. In England, a diagnosis rate for chlamydia is included in the Public Health Outcomes Framework [29], used by sexual health commissioners to plan work aimed at achieving recommended testing rates (2,300 per 100,000 population) [30]. In response to that, some Local Commissioners in England choose to incentivise GPs to screen more patients by paying them to reach diagnostic targets, and/or encourage GPs to screen by stressing the importance of screening as a public health measure.

In Estonia, health care service costs are covered by National health insurance. The limited budget leads to prioritisation of resources to other areas as STI care is generally a low priority for GPs.

In Sweden, chlamydia care at GP level is provided within the capitation for registered patients, i.e. covered by the County Council. Further, some counties provide chlamydia diagnostic tests free of charge to the GP (e.g. Örebro County but not Uppsala County). The patients can go in every county to any GP for testing and treatment without incurring any cost.

In France patients pay GPs and laboratories directly for services rendered and afterwards are partially reimbursed by the National health insurance system. However, only $65 \%$ of the cost for opportunistic testing is reimbursed to patients belonging to risk groups only (although these risk groups are not specified). Testing is free for patents in STI, family planning and antenatal clinics.

In Estonia, 50\% of the STI treatment medication costs are reimbursed to patients, and in England, patients do not have to pay for the medication if they are treated by a Genitourinary Medicine clinic, they are in full time education and under 18 years of age, in receipt of certain benefits, or are prescribed treatment under a Patient Group Direction.

\section{Discussion}

Our aim was to compare chlamydia care in countries where testing is provided by most GP practices (England, Sweden) with that in countries where GP testing is not provided or is provided only to a very limited extent (France, Estonia) to delineate factors that may be related to the future scope and volume of chlamydia care provided by GPs. 
Table 2 Chlamydia management and control activities in study countries

\begin{tabular}{lc}
\hline & England \\
\hline $\begin{array}{l}\text { Written guidelines or recommendations } \\
\text { about chlamydia diagnosis and } \\
\text { case management }\end{array}$ & UK National Guideline for the \\
& Management of Genital Tract \\
Infection with Chlamydia \\
trachomatis (2006) \\
British Association for Sexual \\
Health and HIV (BASHH), 2006 \\
National Chlamydia Screening \\
Programme Core Guidance \\
6th Edition 2012
\end{tabular}

Guidelines recommend testing

for asymptomatic people

Repeat test recommended for

patients with a positive

chlamydia test

Additional testing for other STIs

or HIV recommended for those

with positive chlamydia test

Partner notification recommended

Written guidelines or recommendation about chlamydia diagnosis and case management specifically for GPs

National chlamydia screening program

National surveillance data for chlamydia routinely reported

Chlamydia cases reported by

Settings providing chlamydia testing (GUM = genitourinary medicine clinic;

$\mathrm{STI}=$ sexually transmitted infections

clinics; GYN = gynecology clinics)

\section{Estonia}

France

Sweden

Estonian Union against 2010: Health authority

2010: Health authority
recommendations on laboratory

diagnostic procedure only

Sexually Transmitted

Infections (EUSTI), 201

The Board of County

Medical Officers 2010

Yes

Yes

Since 2003: recommendations for screening at- risk women aged 15-25 [32]

No

Repeat test of positives 3

months after diagnosis

Yes

Repeat test of positives

3 months after diagnosis

Yes

Including HIV

Yes (patient referral)

No

Yes (patient referral)

No

Yes, contained within National Chlamydia Screening Programme Core Guidance 6th Edition 2012 and BASHH 2006

Royal College of General Practitioners 2013 Sexually Transmitted Infections in primary care guidelines

Yes

Yes

Laboratories

GUM, sexual and reproductive health services, GPs, pharmacies, termination of pregnancy providers, internet based

Youth Health Centres; self-sampling;
Test for cure

Yes

Yes (patient and provider referral)

Yes, Recommendations from the Board of County Medical officers, 2010

No (Not routinely, but intermittently)

Surveillance network of volunteer (not compulsory, not reimbursed) laboratories that report detection rates of chlamydia (ReNaChla) GYN; STI; internet based
GP; STI, GYN; Family planning clinic; Internal medicine specialist 
Table 2 Chlamydia management and control activities in study countries (Continued)

\begin{tabular}{|c|c|c|c|c|}
\hline & $\begin{array}{c}\text { services, other (including targeted } \\
\text { youth services) }\end{array}$ & & & \\
\hline \multirow[t]{3}{*}{ Main site for chlamydia testing } & $\begin{array}{l}\text { Men/women - GUM, primary } \\
\text { care settings including GP }\end{array}$ & Women - GYN; & Youth - free and & Women: Family planning \\
\hline & & Men - STI clinic & anonymous family & or GP Men: STI clinic or GP \\
\hline & & $\begin{array}{l}\text { Youth - Youth } \\
\text { health centres }\end{array}$ & planning clinics & Youth - Youth surgeries \\
\hline \multirow{4}{*}{$\begin{array}{l}\text { Breakdown of chlamydia cases by } \\
\text { setting for diagnosis or } \\
\text { treatment (top 3) }\end{array}$} & STI/GUM 29\% & STI 20\% & Presumed to originate & STI $25 \%$ \\
\hline & GP $18 \%$ & GP 6\% & mainly from Youth Health & GP $10 \%$ \\
\hline & Family planning 15\% & $\begin{array}{l}\text { Youth Health } \\
\text { Centres 30\% }\end{array}$ & Centres and STI, Family & Youth Health Centres 40\% \\
\hline & Other 33\% & GYN 30\% & planning clinics & \\
\hline
\end{tabular}


Table 3 Primary health care provision indicators in study countries

\begin{tabular}{|c|c|c|c|c|}
\hline & England & Estonia & France & Sweden \\
\hline \multirow[t]{2}{*}{$\begin{array}{l}\text { Number of general practitioners } \\
\text { premises/surgeries }\end{array}$} & 8230 in England & 802 & $\begin{array}{l}59838 \text { GPs registered in } \\
\text { private practices }\end{array}$ & 5000 \\
\hline & 70 per 100000 & 62 per 100000 & 92 per 100000 & 53 per 100000 \\
\hline \multirow[t]{2}{*}{ Main type of GP services } & $\begin{array}{c}\text { Small group practices: typically 2-3 GPs and } \\
\text { nurses (45\%); larger ones 5-9 GPs and } \\
\text { 3-4 nurses (38\%) }\end{array}$ & $\begin{array}{l}\text { Single handed practices }(70 \%) \text {; small } \\
\text { group practices (20\%); } 1-2 \text { nurses }\end{array}$ & $\begin{array}{l}\text { Small group practices (54\%), } \\
\text { others single handed. }\end{array}$ & $\begin{array}{c}\text { Medium size practices: } 4-5 \text { GPs, } 10 \\
\text { nurses, } 2 \text { lab technicians, one social } \\
\text { worker }\end{array}$ \\
\hline & & & No nurses & \\
\hline $\begin{array}{l}\text { Is training for sexually transmitted disease } \\
\text { care (during residency) mandatory for GPs? }\end{array}$ & $\begin{array}{l}\text { Not mandatory, but GPs studying it } \\
\text { must meet key competencies }\end{array}$ & Yes (but extremely limited) & No & No, but often done \\
\hline $\begin{array}{l}\text { Proportion of people aged } 16-24 \\
\text { visiting GP per year }\end{array}$ & $75 \%$ female, $63 \%$ male\% [26] & $71 \%[27]$ & $75 \%[28]$ & $60 \% *$ \\
\hline
\end{tabular}


Table 4 Chlamydia care in GP practices in study countries

\begin{tabular}{|c|c|c|c|c|}
\hline & England & Estonia & France & Sweden \\
\hline $\begin{array}{l}\text { GPs regularly provide STI } \\
\text { care including chlamydia }\end{array}$ & Yes & No & $\begin{array}{l}\text { Yes, usually only for } \\
\text { symptomatic cases }\end{array}$ & Yes \\
\hline $\begin{array}{l}\% \text { of GP services performing } \\
\text { any testing for genital } \\
\text { CT infection }\end{array}$ & $88 \%$ & $<5 \%$ & $<10 \%$ & $>80 \%$ \\
\hline $\begin{array}{l}\text { Do GP services provide } \\
\text { screening (i.e. testing } \\
\text { asymptomatic cases } \\
\text { for chlamydia)? }\end{array}$ & Yes & No & No & Yes \\
\hline $\begin{array}{l}\text { Do GP services test } \\
\text { symptomatic cases for } \\
\text { chlamydia? }\end{array}$ & Yes & No & No & $\begin{array}{l}\text { Yes (on the request } \\
\text { of the patient) }\end{array}$ \\
\hline $\begin{array}{l}\text { Most commonly used } \\
\text { method for chlamydia } \\
\text { testing in GP settings }\end{array}$ & NAAT* $^{*}$ & NAAT & NAAT & NAAT \\
\hline $\begin{array}{l}\text { Specimens usually used } \\
\text { by GPs for diagnosis of } \\
\text { symptomatic cases }\end{array}$ & $\begin{array}{l}\text { Men urine; Women - } \\
\text { physician collected } \\
\text { cervical swab }\end{array}$ & $\begin{array}{l}\text { Men - urine or physician } \\
\text { collected urethral swab; } \\
\text { Women - physician } \\
\text { collected cervical swab }\end{array}$ & $\begin{array}{l}\text { Men urine; Women - physician } \\
\text { collected cervical swab }\end{array}$ & $\begin{array}{c}\text { Men urine; Women - cervical } \\
\text { swab or (self-collected) } \\
\text { vaginal swabs }\end{array}$ \\
\hline $\begin{array}{l}\text { Specimens usually used } \\
\text { by GPs for screening tests }\end{array}$ & $\begin{array}{l}\text { Men urine; Women - } \\
\text { (self-collected) vaginal } \\
\text { swabs or urine }\end{array}$ & $\begin{array}{l}\text { Men - urine or physician } \\
\text { collected urethral swab; } \\
\text { women - physician collected } \\
\text { swab (endocervical) or urine }\end{array}$ & $\begin{array}{l}\text { Men - urine samples: women - } \\
\text { physician collected } \\
\text { swab (endocervical) }\end{array}$ & $\begin{array}{l}\text { Men urine; Women - } \\
\text { (self- collected) } \\
\text { vaginal swabs }\end{array}$ \\
\hline
\end{tabular}

*Nucleic acid amplification tes.

We found little significant difference in the burden of the disease (genital chlamydia infection) or the organization of GP care provision. In all four countries, a substantial proportion $(\sim 70 \%)$ of population at most risk of chlamydia (young people aged 16-25 years) annually visit GPs. Importantly, in all the countries examined, testing for chlamydia is available in the public sector, and using NAAT methodology (NAAT is convenient, logistically straightforward, facilitates sampling, and highly specific/sensitive). An important similarity was that chlamydia care costs are reimbursed to the relevant parties (GPs in England, Sweden and Estonia; and patients in France) by the National health insurance system or its equivalent in participating countries (although not necessarily all the costs).

The countries where GPs provide chlamydia care regularly (England, Sweden) have written chlamydia management guidelines developed specifically for GPs, and STI management was more firmly established in the GP training curriculum either formally (England) or informally (Sweden). In comparison, in France, training for sexually transmitted disease care during GP training was not mandatory and in Estonia training was extremely limited (although formally in place).

A prerequisite for effective chlamydia control is the existence of a comprehensive and effective control programme, with a broad consensus on a strategy for chlamydia control, taking into account specific national opportunities and limitations, and addressing available and future services and resources. National strategies or plans on STI control that specifically mention chlamydia are in force in England and Sweden. England is the only country in the European Union implementing a national chlamydia screening program that offers opportunistic screening for chlamydia to women and men under 25 years of age attending clinical and non-clinical screening venues using non-invasive urine or vulvo-vaginal swab samples tested via NAAT [31]. In addition and in relation to that, England has specific chlamydia diagnostic targets for local authorities to reach and therefore this incentivises them to take forward chlamydia Screening Programmes with GPs.

Table 5 Payment for chlamydia and STI care in GP settings

\begin{tabular}{|c|c|c|c|c|}
\hline & England & Estonia & France & Sweden \\
\hline \multirow{2}{*}{$\begin{array}{l}\text { Are any of the costs of [health care services } \\
\text { for the diagnosis and treatment of individuals } \\
\text { with chlamydia] covered or reimbursed to the } \\
\text { GP service by the national health insurance } \\
\text { system or its equivalent? }\end{array}$} & Yes & Yes & Yes, indirectly & Yes \\
\hline & National Health Service & $\begin{array}{l}\text { Estonian health } \\
\text { insurance fund }\end{array}$ & $\begin{array}{l}\text { Patients pay for directly to GPs for } \\
\text { chlamydia care, and are afterwards } \\
\text { (partially) reimbursed by } \\
\text { the National health insurance }\end{array}$ & County Council \\
\hline $\begin{array}{l}\text { Are the costs of }[\ldots] \text { covered or } \\
\text { reimbursed to patients? }\end{array}$ & Yes & $\begin{array}{c}\text { Yes, partially } \\
\text { (drugs up to 50\%) }\end{array}$ & Yes, partially (all services up to 65\%) & Yes \\
\hline
\end{tabular}


The historical provision of STI care influences current GP staff attitudes and confidence to provide chlamydia testing in the primary care setting. In all countries the majority of STI diagnostic tests have been undertaken in the specialised genito-urinary medicine or youth/family planning of gynaecology settings. And indeed this continues to be the major provider of chlamydia testing, but we contend that the GP practice could play a much greater role. Chlamydia screening as a national program has only been undertaken in England since 2003 and is not yet embedded as routine [32]. In Estonia and France it may be difficult to change long-term traditions, especially when the special training is limited. An intervention study conducted in the South West of England was successful in increasing chlamydia testing rates in general practice through providing training, resources and support to GP staff [33]. The results of this study were intended to inform the adaptation of that intervention to implement a chlamydia testing training package for with general practice staff in England, Estonia, France and Sweden to ensure cultural and logistical issues were addressed in its development.

A recent review on potential advantages of chlamydia screening concluded that young people are generally positive about chlamydia screening, and general practice could be one of their preferred venues [34].

Several studies assessing care provision in GP surgeries have documented substantial barriers for the delivery of preventive services - such as lack of time during the visit, inadequate insurance reimbursement, belief that patient will not wish to discuss or comply with recommendations, and lack of physician expertise in counselling techniques [35]. Consistent with the finding that time is a salient barrier, Zyzanski and colleagues have shown that high-volume physicians perform fewer preventive services [36]. A study from the USA, has shown that to fully satisfy the US Preventive Services Task Force recommendations, 1,773 hours of a physician's annual time, or 7.4 hours per working day, is needed for the provision of preventive services [35]. This confirms that time may well be a major barrier to public health initiatives in primary care and emphasises the need for prioritising interventions to be delivered and any intervention to be quick and easy.

Our study has limitations. A significant limitation is that we did not examine individual features of primary prevention present in the study countries. Further, we only assessed a small number of countries, and we are not able to generalise our results widely. However, we believe that this analysis has provided useful insights in an area where research is limited.

\section{Conclusions}

In countries where chlamydia testing is provided by GPs (England, Sweden) a national strategy or plan on STI control that specifically mentions chlamydia was in force, chlamydia care guidelines for GPs were in place and STI management was more firmly established in the GP residency training curriculum, either formally (England) or informally (Sweden), than in the other countries.

Future research on the effectiveness of chlamydia screening (also in the context of general practice care) and program provision should reflect national needs and the prevention of complications. Our findings indicate that to attain any increase in the provision of testing for and diagnosis of STIs in the general practice setting countries with low chlamydia and STI testing will probably need nationally agreed guidance, nationally agreed STI training within the GP residency curriculum, and much on-going education support and finances within the general practice setting. We are now developing an educational resource that can be implemented across countries with different chlamydia and STI testing provision in the GP setting (www.STItraining.eu).

\section{Additional file}

Additional file 1: Questionnaire used for study data collection.

\section{Competing interest}

The authors declare that they have no competing interest.

\section{Authors' contribution}

$A U, E J R$ and CMCN designed the study and the data collection form. All authors contributed to the actual data collection. AU planned the analysis, and organized the data for analysis, and wrote the first draft of the manuscript. All authors contributed to revising the manuscript and have approved the final manuscript.

\section{Acknowledgement}

This study was supported by Leonardo Da Vinci Lifelong learning programme project Chlamydia Testing Training in Europe (number 2012-1-GB2-LEO05.08044).

\section{Author details}

${ }^{1}$ Department of Public Health, University of Tartu, Tartu, Estonia. ${ }^{2}$ Public Health England, Primary Care Unit, Microbiology, Gloucestershire Royal Hospital, Gloucester, UK. ${ }^{3}$ Polyclinic, University of Tartu, Tartu, Estonia. ${ }^{4}$ Clinical Microbiology, Örebro University Hospital, Örebro, Sweden. ${ }^{5}$ Office for Communicable Disease Control, Uppsala County Council, Uppsala, Sweden. ${ }^{6}$ Nice University Hospital, Nice, France.

Received: 17 January 2014 Accepted: 27 October 2014

Published: 5 November 2014

\section{References}

1. European Centre for Disease Prevention and Control: Annual epidemiological report Reporting on 2010 surveillance data and 2011 epidemic intelligence data. Stockholm: ECDC; 2012.

2. Centers for Disease Control and Prevention: Sexually Transmitted Disease Surveillance 2010. Atlanta: U.S: Department of Health and Human Services; 2011.

3. European Centre for Disease Prevention: (Draft) technical report: Chlamydia Control in Europe Survey of Member States. Stockholm: ECDC; 2013.

4. European Centre for Disease Prevention and Control: GUIDANCE Chlamydia control in Europe. Stockholm: ECDC; 2009. available at http://ecdc.europa.eu/ en/publications/publications/0906_gui_chlamydia_control_in_europe.pdf.

5. Shaw K, Coleman D, O'Sullivan M, Stephens N: Public health policies and management strategies for genital Chlamydia trachomatis infection. Risk Manage Healthc Policy 2011, 4:57-65. 
6. Kalwij S, French S, Mugezi R, Baraitser P: Using educational outreach and a financial incentive to increase general practices' contribution to chlamydia screening in South-East London 2003-2011. BMC Public Health 2012, 12:802.

7. National Chlamydia Screening Programme Standards. 6th edition; 2012. available at http://www.chlamydiascreening.nhs.uk/ps/resources/corerequirements/NCSP\%20Standards\%206th\%20Edition_October\%202012.pdf.

8. Guy RJ, Ali H, Liu B, Poznanski S, Ward J, Donovan B, Kaldor J, Hocking J: Efficacy of interventions to increase the uptake of chlamydia screening in primary care: a systematic review. BMC Infect Dis 2011, 11:211.

9. Ginige S, Fairley CK, Hocking JS, Bowden FJ, Chen MY: Interventions for increasing chlamydia screening in primary care: a review. BMC Public Health 2007, 7:95.

10. McNulty CA, Thomas M, Bowen J, Buckley C, Charlett A, Gelb D, Foy C, Sloss $\mathrm{J}$, Smellie S: Interactive workshops increase chlamydia testing in primary care-a controlled study. Fam Pract 2008, 25(4):279-86

11. Roland M, Guthrie B, Thome DC: Primary Medical Care in the United Kingdom. J Am Board Fam Med 2012, 25(1):S6-S11.

12. Samuelson M, Bourgueil Y: Country Case Study: Primary care in France. In Presentation at the Conference Improving primary care in Europe and the US. Italy: Towards patient-centered, proactive and coordinated systems of care; 2008.

13. Glenngård AH, Hjalte F, Svensson M, Anell A, Bankauskaite V: Health systems in transition. Sweden: $\mathrm{WHO}$, on behalf of the European Observatory on Health Systems and Policies; 2005.

14. European Centre for Disease Prevention and Control: Annual Epidemiological Report 2012. Reporting on 2010 surveillance data and 2011 epidemic intelligence data. Stockholm: 2013. available at http://ecdc.europa.eu/en/ publications/Publications/Annual-Epidemiological-Report-2012.pdf.

15. European Centre for Disease Prevention: Technical report re view of chlamydia control activities in EU countries. Stockholm: ECDC; 2008.

16. Goulet V, de Barbeyrac B, Raherison S, Prudhomme M, Semaille C, Warszawski J: CSF group: Prevalence of Chlamydia trachomatis: results from the first national population-based survey in France. Sex Transm Infect 2010, 86(4):263-70

17. Low N, McCarthy A, Macleod J, Salisbury C, Campbell R, Roberts TE, Horner P, Skidmore S, Sterne JA, Sanford E, Ibrahim F, Holloway A, Patel R, Barton PM, Robinson SM, Mills N, Graham A, Herring A, Caul EO, Davey Smith G, Hobbs FD, Ross JD, Egger M, Chlamydia Screening Studies Project Group: Epidemiological, social, diagnostic and economic evaluation of population screening for genital chlamydial infection. Health Technol Assess 2007, 11(8):1-165. iii-iv, ix-xii.

18. Bracebridge S, Bachmann MO, Ramkhelawon K, Woolnough A: Evaluation of a systematic postal screening and treatment service for genital Chlamydia trachomatis, with remote clinic access via the internet: a crosssectional study, East of England. Sex Transm Infect 2012, 88(5):375-81.

19. Uusküla A, Kals M, Denks K, Nurm U, Kasesalu L, Dehovitz J, McNutt LA: The prevalence of chlamydial infection in Estonia: a population-based survey. Int J STD AIDS 2008, 19(7):455-8.

20. British Association Sexual Health and HIV 2006: UK National Guideline for the Management of Genital Tract Infection with Chlamydia trachomatis. ; 2006. http://www.bashh.org/documents/65.pdf.

21. Sweden STI management guidelines; available at http://www.slf.se/ Foreningarnasstartsidor/Intresseforening/Smittskyddslakarforeningen/ Smittskyddsblad-/Klamydialakarinformation-2010-02-15/, in Swedish.

22. Estonian union for sexually transmitted infections: STI management guidelines 2011; 2011. http://www.eusti.ee/STI_ravijuhis_2011.pdf.

23. Haute autorite de sante 2010 Diagnostic biologique de linfection à Chlamydia trachomatis; 2012. http://www.has-sante.fr/portail/upload/docs/application/ pdf/2012-02/synthese_chlamydia_trachomatis.pdf.

24. Haute autorite de sante 2003: Evaluation du depistage des infections urogenitales basses à chlamydia trachomatis en France. ; 2003. http://www.hassante.fr/portail/upload/docs/application/pdf/Chlamydia_tome2_synth.pdf.

25. Smittspårning vid sexuellt överförbara sjukdomar: Recommendations on partner notification. Swedish: National Board of Health; 2007.

26. Salisbury C, Macleod J, Egger M, McCarthy A, Patel R, Holloway A, Ibrahim F, Sterne JA, Horner P, Low N: Opportunistic and systematic screening for chlamydia: a study of consultations by young adults in general practice. Br J Gen Pract 2006, 56(523):99-103.

27. Tekkel M, Veideman T: Health Behavior among Estonian Adult Population, 2012. Natl Inst Health Dev 2012, available at https://intra.tai.ee/images/ prints/documents/136479842690_TKU_2012.pdf.
28. Beck F, Richard JB: Les Comportements de santé des jeunes. Analyses du Baromètre santé 2010. Saint-Denis: Inpes, coll. Baromètres santé 2013, 344. available at http://www.inpes.sante.fr/CFESBases/catalogue/pdf/1452.pdf.

29. PHPSU/HIAT/12341: Public Health Outcomes Framework. Department of Health, Public Health Policy and Strategy Unit; 2013. available at https:// www.gov.uk/government/uploads/system/uploads/attachment_data/file/ 263658/2901502_PHOF_Improving_Outcomes_PT1A_v1_1.pdf.

30. Public Health Outcomes Framework 2013 to 2016 and technical updates. England: Department of Health; available at https://www.gov.uk/ government/publications/healthy-lives-healthy-people-improving-outcomesand-supporting-transparency.

31. National Chlamydia Screening Programme; http://www.chlamydiascreening.nhs.uk/.

32. Dehne KL, Riedner G, Neckermann C, Mykyev O, Ndowa FJ, LaukammJosten U: A survey of STI policies and programmes in Europe: preliminary results. Sex Transm Infect 2002, 78:380-384.

33. McNulty CA, Hogan AH, Ricketts EJ, Wallace L, Oliver I, Campbell R, Kalwij S, $\mathrm{O}^{\prime}$ Connell $\mathrm{E}$, Charlett A: Increasing chlamydia screening tests in general practice: a modified Zelen prospective Cluster Randomised Controlled Trial evaluating a complex intervention based on the Theory of Planned Behaviour. Sex Transm Infect 2013, Sep 4. [Epub ahead of print].

34. Perkins E, Carlisle C, Jackson N: Opportunistic screening for Chlamydia in general practice: the experience of health professionals. Health Soc Care Community 2003, 11(4):314-20.

35. Yarnall KS, Pollak KI, Østbye T, Krause KM, Michener JL: Primary care: is there enough time for prevention? Am J Public Health 2003, 93(4):635-41.

36. Zyzanski SJ, Stange KC, Langa D, Flocke SA: Trade-offs in high-volume primary care practice. J Fam Pract 1998, 46:397-402.

doi:10.1186/1471-2458-14-1147

Cite this article as: Uusküla et al.: Provision of chlamydia testing, and training of primary health care staff about chlamydia testing, across four European countries. BMC Public Health 2014 14:1147.

\section{Submit your next manuscript to BioMed Central and take full advantage of:}

- Convenient online submission

- Thorough peer review

- No space constraints or color figure charges

- Immediate publication on acceptance

- Inclusion in PubMed, CAS, Scopus and Google Scholar

- Research which is freely available for redistribution

Submit your manuscript at www.biomedcentral.com/submit
C Biomed Central 